\title{
Prominent seasonality of 25(OH)D vitamin deficiency in Latvia: Age and gender-related variations and testing regimen
}

\author{
Sergey Nikulshin ${ }^{1, *}$, Jana Osite ${ }^{2}$, Stella Lapina ${ }^{2}$, Anda Krisane $^{3}$, Iveta Dzivite-Krisane ${ }^{1}$, \\ and Dace Gardovska ${ }^{1}$ \\ ${ }^{1}$ Riga Stradins University, Riga, Latvia \\ ${ }^{2}$ Central Laboratory, Riga, Latvia \\ ${ }^{3}$ E. Gulbja Laboratory, Riga, Latvia
}

\begin{abstract}
Seasonality of $25(\mathrm{OH}) \mathrm{D}$ deficiency rate is a factor of major clinical and social impact and should be considered when planning for appropriate testing and tailored correction. We present retrospective cross-sectional analysis of over a million $25(\mathrm{OH}) \mathrm{D}$ tests performed in two leading Latvian laboratories Central Laboratory and E.Gulbja Laboratory. Both series of tests demonstrated prominent seasonal variability of $25(\mathrm{OH})$ D deficiency rate $(<20 \mathrm{ng} / \mathrm{ml})$ and critical deficiency rate $(<12 \mathrm{ng} / \mathrm{ml})$ : the lowest percentage of deficient tests was in August, while a significant peak was found in March-April. This trend was present at all ages and in both genders, variations were pronounced even for a high-latitude country and more prominent for critical deficiency, in younger age groups and in males. Analysis of testing regimens of both laboratories revealed that schedule was not optimal, period of higher testing intensity being far removed from the 25(OH)D deficiency peak.
\end{abstract}

Key words $-25(\mathrm{OH}) \mathrm{D}$, deficiency, seasonal variations.

\section{Introduction}

Considerable seasonal variations of vitamin $\mathrm{D}$ and its active metabolite $25(\mathrm{OH}) \mathrm{D}$ have been described in 1970-ies, with insolation level proven as the main contributing factor, more important than diet or race $[1,2]$. The phenomenon was later confirmed by extensive crosssectional and longitudinal analysis [3-8]. These variations are more pronounced in countries with seasonal climate and particularly in high-latitude regions, where most studies note minimal level of $25(\mathrm{OH}) \mathrm{D}$ and maximal deficiency rate in winter or early spring, and maximal level with matching drop of deficiency rate in late summer [5-7, 9, 10, 11,]. Age and genderrelated differences have been reported, though contradictory $[5,6,9]$.

Insufficient vitamin D is directly associated with morbidity and severity of various diseases, including cardiovascular, endocrine, inflammatory and autoimmune disorders, tumors, infections (including COVID-19), mental disorders and others; moreover, 25(OH)D deficiency has been related to increased mortality [11-14]; on the other hand, it is effectively treatable by oral supplements $[5,8]$. Thus, seasonal variations that assume the existence

\footnotetext{
*Corresponding author: sergejs.nikulsins@ rsu.lv
} 
of a predictable cyclic time zone of additional health risks are of medical and social consequence. Evidently, it should be considered by any national testing and correction program, particularly in higher-latitude countries.

Ethnic, social and nutritional factors may affect vitamin D status and seasonality $[5,10$, 15]; meaning that findings of population-based studies are not completely applicable to cohorts in other countries, and that national surveys are required.

We present results of the first comprehensive study of seasonal variability of $25(\mathrm{OH}) \mathrm{D}$ deficiency rate in Latvia. Analyzing a large number of tests, we studied monthly dynamics of $25(\mathrm{OH}) \mathrm{D}$ level in age groups and genders; in addition, we examined variations of testing intensity and compared them to the $25(\mathrm{OH}) \mathrm{D}$ level curve to evaluate effectiveness of the current testing regimen.

\section{Methods}

Anonymous test results from laboratory information systems of two leading Latvian laboratories were assessed - Central Laboratory (CL, complete series of410427 tests performed in 2014-2019) and E.Gulbja Laboratory (EGL, complete series of849739 tests performed in 2012-2019). Supplied information included 25(OH)D level, age, gender and registration date (month).

25(OH)D deficiency was considered at levels below $20 \mathrm{ng} / \mathrm{ml}$, and critical deficiency at levels below $12 \mathrm{ng} / \mathrm{ml}[8,16,17]$.

The series where split into genders (F:M ratio was 2.89 in CL and 2.54 in EGL) and into four age groups: children (age 0-17, CL $11.6 \%$ and EGL 15.7\%), young adults (age 1839, CL 22.0\% and EGL 31.4\%), middle-aged (age 40-69, CL 49.1\% and EGL 43.5\%) and elderly (age 70and over, CL $17.3 \%$ and EGL 9.4\%).

MS Excel was used for general data management. Variations were evaluated as relative difference, calculated as (maximal rate - minimal rate) $/$ minimal rate $\times 100 \%$. Statistical analysis was performed by IBM SPSS v25 software: Kruskal-Wallis test for $n$ variables for significance of monthly differences, paired Wilcoxon test for differences between gender variations and chi-square test for monthly differences of test counts; significance was assumed at $(p<0.05)$.

\section{Results}

Prominent seasonal variations of $25(\mathrm{OH}) \mathrm{D}$ deficiency rate were found in both CL and EGL data sets (Tables 1 and 2). There were well-defined negative peaks in August for both overall deficiency rate (below $20 \mathrm{ng} / \mathrm{ml}$ ) and critical deficiency (below $12 \mathrm{ng} / \mathrm{ml}$ ), and the highest rates were found in March (CL) or in April (EGL), the positive peaks being less steep. Uneven monthly distribution of deficiency rates in al subgroups was highly significant in KruskalWallis test.

Seasonality was particularly striking in case of critical deficiency rate: almost nonexistent in August in all age groups except the elderly, it increased 20-fold and more in children and young adults. Rise of overall deficiency rate was milder: maximal increase was about 3-4 times in younger age groups and less than 2-fold in the elderly. Of note, improvement of overall deficiency in summer was not as spectacular as nearly total disappearance of critical deficiency, not in a single instance the lowest August rate of deficiency $<20 \mathrm{ng} / \mathrm{ml}$ rate was below $10 \%$.

In both data sets seasonal deviations diminished with age, spring maximum of deficiency rate got flatter, but deficiency rate in August gradually increased, particularly in the elderly, though differences remained highly significant. 
Table 1. Central Laboratory: 25(OH)D deficiency rates by month (\%).

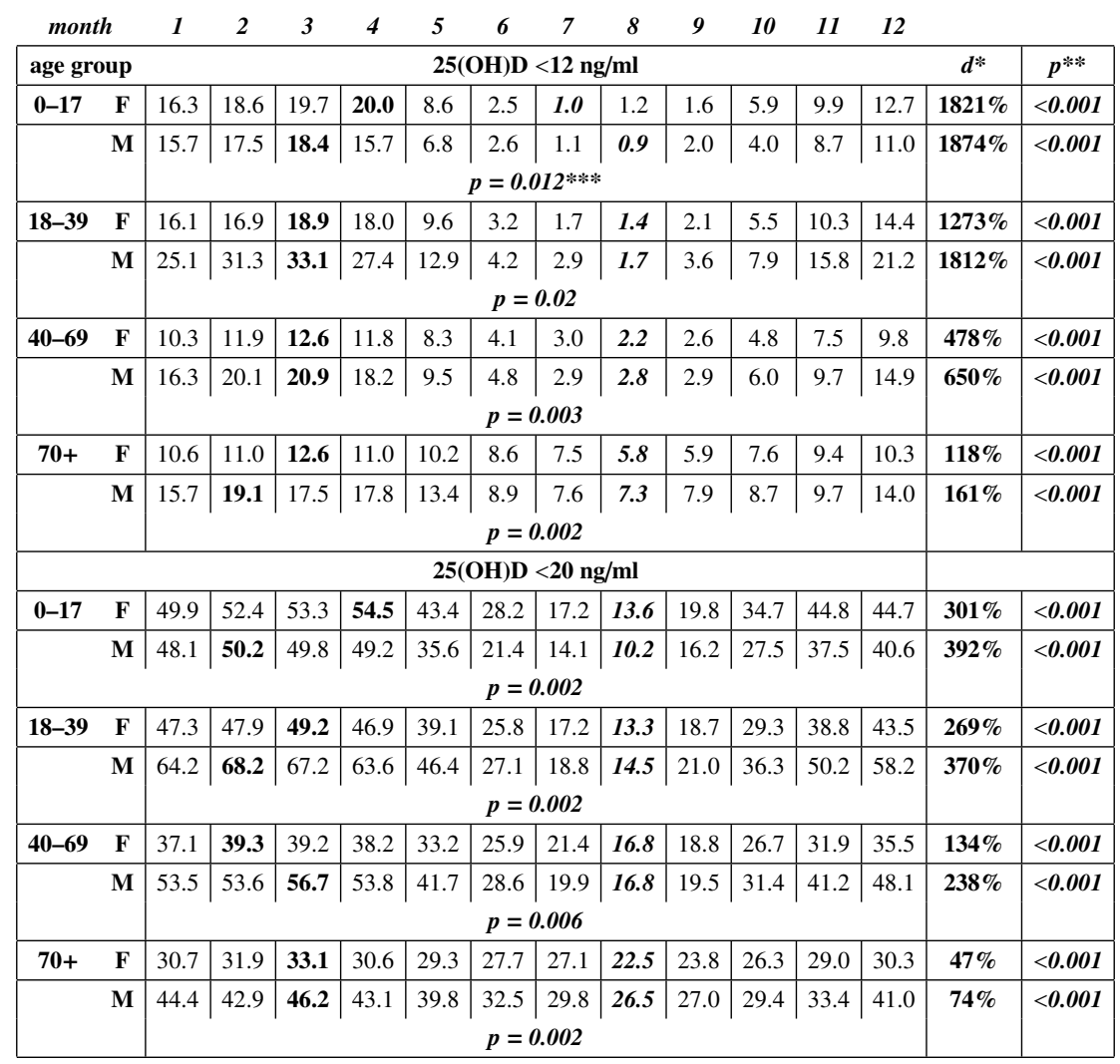

bold - maximal rate, bold italic - minimal rate.

$d^{*}$ - relative difference of maximal and minimal rates

$p^{* *}$ - significance of monthly differences by multivariable Kruskal-Wallis test

$p^{* * *}$ - significance of gender differences by paired Wilcoxon test.

There was a notable gender-related difference in seasonal variations. Minimal August rates were approximately equal in both genders at all ages, the spring peak was slightly higher in girls in 0-17 age group in both data sets, while in all other age groups the spring increase of both overall and critical deficiency rate was much more prominent in males. Differences between genders for both critical and overall deficiency in all age groups were statistically significant in Kruskal-Wallis test when paired by month.

Analysis of testing intensity demonstrated that number of tests varied by month, the irregularity being highly significant in all age and gender groups $(p<0.001)$. Maximal test count in both data sets was higher in autumn and thus was far removed from deficiency maximum (Fig. 1); of note, the pattern was seen in all age groups and both genders.

\section{Discussion}

The analysis included more than one million 25(OH)D tests from two leading Latvian laboratories and thus covered a significant portion of Latvian population in 2012-2019. There are limitations in the study design: the cohort is not all-inclusive, no longitudinal follow-up was performed for ethical reasons, important biological factors like supplement intake and city 
Table 2. E. Gulbja Laboratory: 25(OH)D deficiency rates by month (\%).

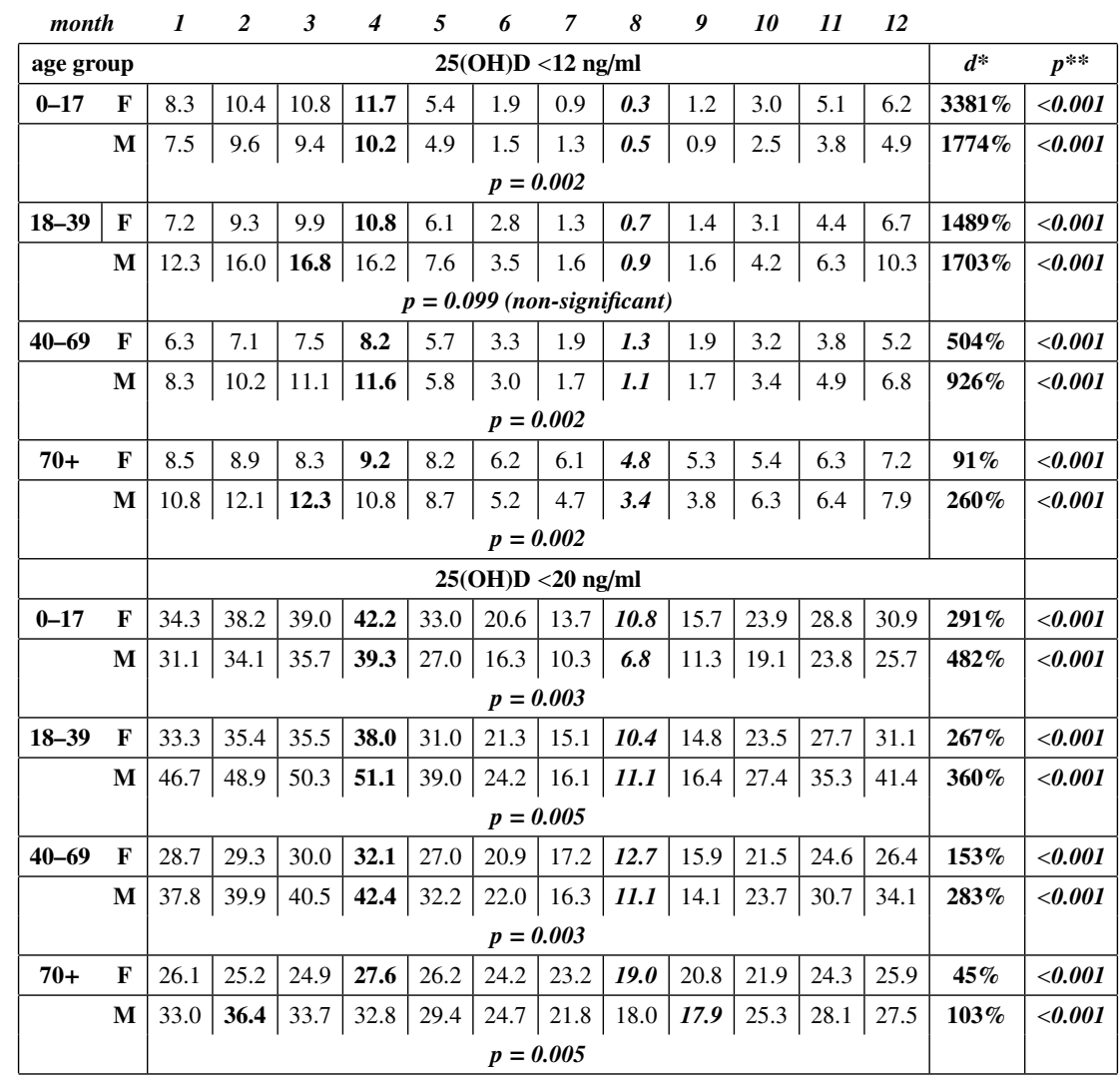

bold - maximal rate, bold italic - minimal rate.

$d^{*}$ - relative difference of maximal and minimal rates

$p^{* *}$ - significance of monthly differences by multivariable Kruskal-Wallis test

$p^{* * *}$ - significance of gender differences by paired Wilcoxon test.

or countryside dwelling, social status, etc. were omitted. Splitting into smaller age groups (particularly in children) could provide additional information. Finally, information on dynamics of the findings during the assessed 8 years would be important to estimate the effect of widespread administering of supplements in recent years. It should be stressed that testing platforms and target populations were different in CL and EGL, so results could not be directly compared. Still, the study revealed several conspicuous common features with evident medical and social impact.

Both data sets demonstrated a considerable proportion of $25(\mathrm{OH}) \mathrm{D}$-deficient tests similar to other European studies [5, 8] with prominent seasonality. Deficiency rate increased in late winter/early spring with peaks in March in CL series and in April in EGL series, and normalized in late summer; this pattern of $25(\mathrm{OH}) \mathrm{D}$ level following insolation with delay of one-two months is typical for northern countries [5, 6, 9, 11, 13]. The dynamics was particularly dramatic for critical deficiency below $12 \mathrm{ng} / \mathrm{mlin}$ younger cohorts, in both series difference of more than 10 times between minimal and maximal rates was found in age groups below 40 years old. It was more prominent than reported elsewhere and may be related, besides biological factors, to insufficient coverage by supplement therapy. 


\section{Central Laboratory}



\section{E. Gulbja Laboratory}

Age Females

Males

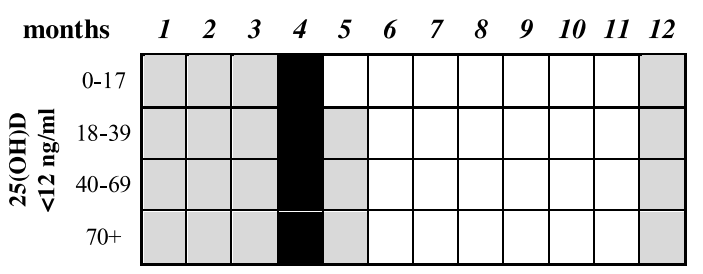

$\begin{array}{llllllllllll}1 & 2 & 3 & 4 & 5 & 6 & 7 & 8 & 9 & 10 & 11 & 12\end{array}$
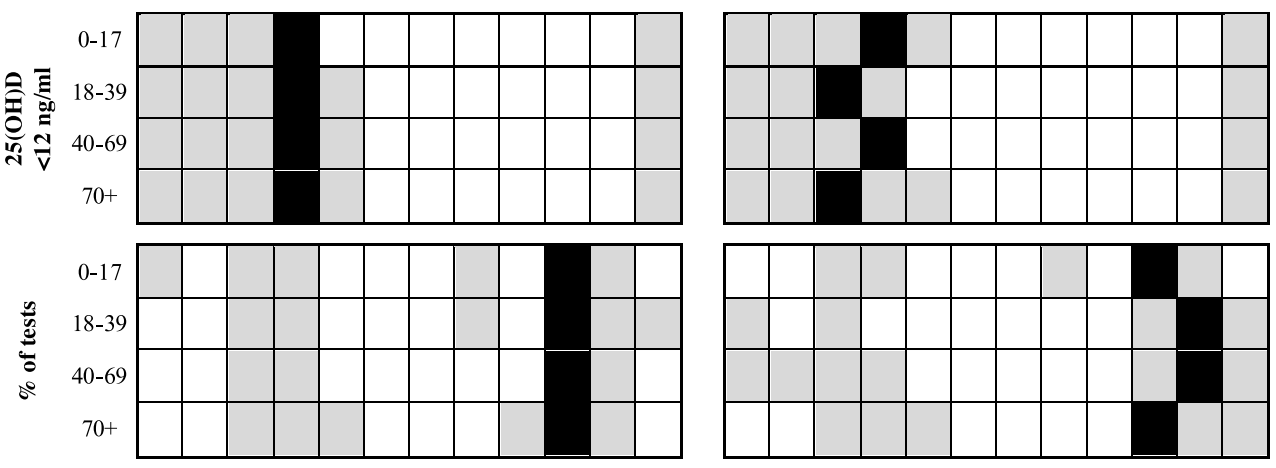

Figure 1. Comparison of critical 25(OH)D deficiency and testing intensity peaks in the studied series, by age groups and genders (shaded grey- months when deficiency and testing were above yearly rate, black - peak months).

Both deficiency rate and seasonal variations in adults were significantly higher in males (maximal deficiency rates 1.5-2 times higher than in females); that is more pronounced than reported in neighbor Estonia, Denmark or Sweden $[5,6,9,11]$ and could be caused, besides biology, by differences in lifestyle and medical coverage. Since $25(\mathrm{OH}) \mathrm{D}$ deficiency has been linked to higher mortality in many studies, this discrepancy in Latvia may be among factors causing the second-highest in Europe gender-related difference of life expectancy [18].

Analysis of testing regimen in both laboratories revealed that the most intensive testing occurs in October-November, when 25(OH)D deficiency rate is still low, being removed from the August minimum for only two or three months. Another example of inappropriate schedule is more intensive testing of children in August, found in both data sets. This gap between deficiency and testing peaks is clinically unfounded, does not fully reflect true 25(OH)D status, moreover, results acquired at the time may be misleading for patients who tend to develop 
deficiency later. Reasons for these arrangements are not clear, the inconsistencies may be related to preferences of clients or doctors, but the fact that regimens are analogous in both laboratories, in both genders and in all age groups indicates a systemic oversight.

Another common feature of both data sets is striking female prevalence in all age groups, except children (74\% females in CL and $72 \%$ in EGL series). Thus, males, apart from presenting with higher deficiency rates and with more prominent seasonal variations are evidently under tested. $25(\mathrm{OH}) \mathrm{D}$ deficiency is as much hazardous for men, that makes insufficient testing a social challenge.

\section{Conclusions}

The first comprehensive cross-sectional study of $25(\mathrm{OH}) \mathrm{D}$ deficiency in Latvia was performed by bulk data analysis and revealed trends that are common for countries with cyclic insolation and diet - significant deficiency rate and prominent seasonality.

Seasonal variations followed similar pattern in both genders and all age groups: deficiency rate was the lowest in August and gradually increased afterwards, reaching peak in March-April. This seasonality was more evident at younger age and in males.

The study revealed a systemic discrepancy between the highest rate of $25(\mathrm{OH}) \mathrm{D}$ deficiency in early spring and the highest number of tests performed in autumn. Though the difference in monthly counts was not great, it still indicates a potential for further improvement of testing regimen.

There was a striking female predominance in the studied data sets.

Thus, males, children and younger adults should be considered at risk at 25(OH)D deficiency peak in early spring, and as such may be designated for targeted testing $[16,17]$.

\section{References}

[1] J.G. Haddad, T.J. Hahn. Nature 244 (1973)

[2] T.C.B. Stamp, J.M. Round. Nature 247 (1974)

[3] M.F. Holick, T.C. Chen. Am. J. Clin.Nutr. 87 (2008)

[4] N.M. van Schoor, P. Lips. Best Pract. Res. Clin. Endocrinol. Metab. 25 (2011)

[5] K.D. Cashman, K.G. Dowling, Z. Škrabáková, et al., Am. J. Clin. Nutr. 103 (2016)

[6] M. Kull Jr, R. Kallikorm, A. Tamm, M. Lember. BMC Public Health. 9 (2009)

[7] A. Huotari, K.H. Herzig. Int. J. Circumpolar. Health. 67 (2008)

[8] K. Amrein, M. Scherkl, M. Hoffmann, et al. Eur. J. Clin.Nutr. 74 (2020)

[9] E. Klingberg, G. Oleröd, J. Konar, M. Petzold, O. Hammarsten. Endocrine. 49 (2015)

[10] A.K. Kasahara, R.J. Singh, A. Noymer. PLoS One. 8 (2013)

[11] L. Hansen, A. Tjønneland, B. Køster, et al., Nutrients. 10 (2018)

[12] G. Bjelakovic, L.L. Gluud, D. Nikolova, et al., Cochrane Database Syst. Rev. 10 (2014)

[13] J.E. Manson, N.R. Cook, I.M. Lee, et al., N. Engl. J. Med. 380 (2019)

[14] D. Głąbska, A. Kołota, K. Lachowicz, et al., Nutrients. 13 (2021)

[15] S. Pilz, A. Zittermann, C. Trummer, et al., Endocr. Connect. 8 (2019)

[16] M. Deschasaux, J.C. Souberbielle, V.A. Andreeva, et al., Medicine (Baltimore) 95 (2016)

[17] M.F. Holick, N.C. Binkley, H.A. Bischoff-Ferrari, et al., J. Clin. Endocrinol. Metab. 96 (2011)

[18] EUROSTAT table TPS00205, updated 28/04/2021 